\title{
Sram in krivda v kratki zgodbi »Marija, pomagaj« Suzane Tratnik
}

\section{Alenka Koron}

ZRC SAZU, Inštitut za slovensko literaturo in literarne vede, Novi trg 2, 1000 Ljubljana, Slovenija https://orcid.org/0000-0002-6466-6480

alenka.koron@zrc-sazu.si

Afekti in emocije so že od antike naprej prepoznani kot bistveni del literarne izkušnje, a med prevlado strukturalizma so bili izključeni iz obravnave pripovedne literature. Izrecni interes zanje se je v naratoloških diskurzih pojavil šele v zadnjih desetletjih z nastajajočo paradigmo sodobnih študij afekta. Pri tem so svojo vlogo odigrali različni vplivi, izročilo pojmov v poetiki, retoriki in psihoanalizi, novejši nevroznanstveni, kognitivni in evolucijski pristopi k pripovedi ter še posebej feministična naratologija in kvirovske teoretske konceptualizacije občutij, v zadnjem času pa tudi deleuzovska pojmovanja afekta. V članku se opiram na sinkretični model pripovednega svetotvorja (narrative worldmaking), ki ga je v dialogu z naštetimi vplivi ter upoštevanjem Paula Ricoeura in Bruna Latoura razvila Claudia Breger. Vsvojem branju kratke zgodbe "Marija, pomagaj"iz knjige Noben glas (2016) sodobne pisateljice in lezbične aktivistke Suzane Tratnik skušam v procesu pripovednega svetotvorja sondirati pripovedno produktivnost sramu in krivde kot družbenih afektov ter osvetliti tip bralskega angažmaja, h kateremu vabi njen diskurz.

Ključne besede: zgodba / Tratnik, Suzana / pripovedna tehnika / čustva / afekti / sram / krivda

$\mathrm{V}$ članku ${ }^{1}$ se opiram na konceptualizacije afekta in emocij v novejših naratoloških diskurzih, da bi lahko z njihovo pomočjo analitično sondirala pripovedno produktivnost afektov v kratki zgodbi Suzane Tratnik z naslovom "Marija, pomagaj“ iz zbirke Noben glas (2016). ${ }^{2}$ Prav ta

${ }^{1}$ Članek je nastal v okviru raziskovalnega programa št. P6-0024 (B), ki ga je financirala Javna agencija za raziskovalno dejavnost Republike Slovenije.

${ }^{2}$ To ni moje prvo ukvarjanje $s$ tozadevno problematiko. Tik pred objavo je $\mathrm{v}$ soavtorstvu z Matteom Colombijem napisani članek z naslovom »Queer Emotions? The Narrative Shape of Feelings in Noben glas by Suzana Tratnik and Eskorta by Michal Hvorecký«, ki primerjalno obravnava emocije ter njihovo pripovedno obliko in funkcijo v zadnji kratki zgodbi iz taiste zbirke, naslovljeni Veliko breme, ter v romanu slovaškega pisatelja Michala Hvoreckýja Eskorta. 
kratkoprozna zbirka Suzane Tratnik se zdi namreč za obravnavo afektov in emocij še posebej primerna zato, ker je v vseh zgodbah, torej tudi $\mathrm{v}$ "Mariji, pomagaj«, osrednji lik deklica nekoliko neujemljive starosti, vendar že na meji adolescence, torej prav na robu življenjskega obdobja, ko igrajo čustva še posebej pomembno vlogo, intenzivna spolnoidentitetna refleksija in samorefleksija pa se šele res začenjata.

Preden se posvetim temeljnemu cilju tukajšnjega branja te kratke zgodbe, torej obravnavi pripovedne produktivnosti afektov $\mathrm{v}$ njej, naj prikažem svoja teoretska izhodišča, in sicer nekatera najpomembnejša, $\mathrm{v}$ marsičem tudi divergentna presečišča študijev afekta in naratologije. Ob njihovem zarisu, ki se opira na članka Claudie Breger »Affect and Narratology" (2017) in "Affects in Configuration: A New Approach to Narrative Worldmaking " (2017), pa moram takoj poudariti, da afekt ni nekaj novega $v$ teoriji pripovedi. To postane očitno že, če pomislimo na njegovo izročilo $\mathrm{v}$ retoriki in poetiki ter $\mathrm{v}$ psihoanalitičnih pristopih, ki so vplivali tudi na naratologijo. Kljub tem predhodnim obravnavam predstavlja delo Robyn Warhol Having a Good Cry: Effeminate Feelings and Pop-Culture Forms (2003) svojevrstno prelomnico. V njem je avtorica $\mathrm{v}$ feministično naratološko refleksijo povezala spolno identiteto (gender), afekt, žanr, bralčevo telo in pripovedno formo. R. Warhol je nastopila proti v bistvu še aristotelovskemu globinskemu pojmovanju emocij, ki so ga povzeli tudi sodobni kognitivni pristopi, modernistična estetika in freudovska psihoanaliza, torej proti razumevanju občutij kot zunanjih izrazov notranjih emocij. Predlagala je nov model, ki ga je oprla na spolnoidentitetne in kvirovske študije ter viktorijanske konceptualizacije občutij. Pri tem je izhajala iz Williama Jamesa ter Eve Kosofsky Sedgwick in njene recepcije Silvana Tomkinsa v delu Shame and its Sisters: A Silvan Tomkins Reader (1995), ki ga je E. Kosofsky Sedgwick souredila z Adamom Frankom, in iz performativnega razumevanja razpoloženj, čustev in strasti kot posledic telesnih sprememb. R. Warhol hoče torej razumeti afekt zunaj psihoanalitične paradigme, in prav to je bila temeljna pobuda za študije afekta, pa naj so te kognitivne ali deleuzovske usmeritve. Toda v želji premagati eksplicitni psihoanalitični fokus na seksualnosti je R. Warhol vseeno nekoliko pretiravala, saj - kot opozarja C. Breger v svojem članku - tudi sama ohranja reminiscence psihoanalitičnih koncepcij (prim. Breger, "Affect and Narratology« 237-238). Poleg tega sta tako E. Kosofsky Sedgwick kot R. Warhol uporabljali v svojih domiselnih natančnih branjih pripovednih žanrov in pri poudarjanju odziva dejanskega bralca tudi formalno naravnan instrumentarij izročila retorične analize. Zato sta s svojim pristopom za preučevanje afektov v pripovedih navdihnili tudi bolj 
mejnstrimovske retorične naratologe, kakršna sta npr. James Phelan in Richard Walsh, ${ }^{3}$ čeprav sta se v svojih konceptualizacijah afekta sicer oba oddaljila od njunih pozicij in bolj približala kognitivnim in nevroznanstvenim stališčem.

Kognitivno znanstveni pristopi so se začeli pospešeno posvečati vprašanju emocij in afekta predvsem po letu 2000, kar je morda treba pripisati odkritju "zrcalnih nevronov" (to se je zgodilo šele v devetdesetih letih prejšnjega stoletja) kot generatorjev empatije. Pri tem so se navezali tudi na dognanja razvojne, socialne in evolucijske psihologije. Enega takšnih pristopov je razvil Patrick Colm Hogan v knjigi Affective Narratology: The Emotional Structure of Stories (2011). Kot je razvidno že iz naslova knjige, Hogan uporablja pojma afekt in emocija sinonimno, kar je v ostrem nasprotju z bolj deleuzovsko orientiranimi usmeritvami. ${ }^{4}$ Njegov osrednji poudarek pri naratološki analizi je na obdelavi (plotu), čemur bi nasprotovali feministična in verjetno tudi retorična naratologija. $V$ različnih kulturnih tradicijah in zgodovinskih obdobjih je Hogan prepoznal tri rekurentne zgodbene prototipe, heroičnega, romantičnega in žrtvovanjskega, in jih povezal s sistemi emocij, ki naj bi bili zanje temeljni. Tako naj bi bil npr. ponos temeljna emocija heroične zgodbene strukture. Vsem prototipnim strukturam pa je skupen izhodiščni vzorec normalnosti (normalcy), povezan z domom, in prekinitev normalnosti, ki jo je treba v zgodbi restituirati, ${ }^{5}$ kar jasno izpostavlja začetke in konce skupaj s koherenco zgodbe kot ključne momente zgodbene strukture in - tu se je treba strinjati s C. Breger (»Affect and Narratology« 239) - nakazuje avtorjevo preferenco do tradicionalnih pripovednih oblik.

Hogan se je močno oprl na evolucijsko teorijo in upošteval biološke dejavnike. Vprašanje svetovljenja zgodbe (worlding the story), ki motivira formalistične in kulturne študije pri natančnem branju posameznih besedil ali skupin besedil, ga je manj zanimalo. Toda takšno tipološko modeliranje, kot ga predlagata Hogan in tudi npr. William Flesch v

\footnotetext{
${ }^{3}$ Glej podrobneje James Phelan Experiencing Fiction in Richard Walsh The Rhetoric of Fictionality.

${ }^{4}$ Sama v tem tekstu sledim C. Breger, ki se je z navezavo na Deleuza resda odločila za rabo pojma afekt, vendar se je v duhu svojega sinkretičnega pojmovanja hkrati tudi odmaknila od Briana Massumija, Deleuzovega prevajalca v angleščino, in od njegovega tolmačenja afekta ter pojasnila, da sama pojmuje afekt vključujoče, kot da zaobsega cel spekter od nezavedne jakosti do čustvene izkušnje (prim. Breger, "Affect and Narratology« 250, op. 45).

${ }^{5}$ Hogan s tem v zvezi sicer ne citira Morfologije pravljice, vendar njegovo izhodišče močno spominja na podobno Proppovo začetno stanje v pravljici in sprožitveni odhod od doma.
} 
knjigi Comeuppance: Costly Signaling, Altruistic Punishment, and Other Biological Components of Fiction (2007), je pravzaprav dokaj reduktivno. Pač pa so bile uspešne nekatere druge kognitivne in nevroznanstvene raziskave o presečiščih pripovedi in emocij - te slednje, torej emocije in ne afekti, so namreč termin, ki je večinoma v rabi v kognitivnih študijah. Odmevna je bila knjiga Suzanne Keen Empathy and the Novel (2007), v kateri se je avtorica poleg kognitivnih konceptualizacij lotila še analize pripovedne tehnike $s$ poudarkom na vprašanjih spolne identitete in žanra, podobno kot R. Warhol v knjigi Having a Good Cry.

Kognitivni in nevroznanstveni naratologi, ki jih je navdihnila S. Keen, so prispevali vrsto zanimivih raziskav, sploh kadar so historično kontekstualizirali svoje delo. Toda njihova smer se razlikuje od linije R. Warhol in E. Kosofsky Sedgwick v tem, da njihovi modeli tesno prepletajo emocije in kognicijo, pri tem pa naglašajo zavest in intencionalnost kot nasprotje nezavednemu ter težijo $\mathrm{k}$ domnevi o relativni stabilnosti čustvenega odziva kot bolj ali manj utemeljeni na identiteti - torej prav na tistem jedrnem sebstvu, zoper katerega je nastopila E. Kosofsky Sedgwick.

Deleuzovci, med njimi npr. Brian Massumi, v nasprotju s kognitivnimi istovetenji afekta $\mathrm{z}$ emocijami strogo ločujejo afekt (ki je zanje asubjektiven, asimboličen in ekscesen) od emocije kot subjektivne vsebine, sociolingvističnega fiksiranja lastnosti izkušnje. Po mnenju Claudie Breger pa so deleuzovci pretiravali z ločitvijo afekta od družbenega in od subjekta; Massumi npr. po njenem vztraja pri ireduktibilno telesni in avtomatski naravi afekta, ki si ga ni mogoče lastiti in je torej odporen na kritiko. ${ }^{6}$

Takšni nastavki so oteževali posvajanje Deleuzovega pojma afekt za tekstualne analize, prav to povezavo pa si je postavila za cilj C. Breger v svojem predlogu sinkretične konceptualizacije pripovednega svetotvorja (narrative worldmaking). Z njeno konceptualizacijo je, kot meni, mogoče dvoje: bolje kot pri drugih pristopih sodobne teorije pripovedi povezati posebne, pogosto zelo nestabilne načine, na katere afekt deluje $\mathrm{v}$ retoričnih procesih pripovedne zgradbe in pri branju v specifičnih historičnih kontekstih in žanrih, in drugič, hkrati odpraviti odpor deleuzovskih študijev afekta do ukvarjanja s specifiko pripovedne forme. V nekem smislu se, zlasti kar zadeva vztrajanje pri natančnem branju in interes za afektivno kompleksnost, C. Breger torej vrača $\mathrm{k}$ R. Warhol in E. Kosofsky Sedgwick, hkrati pa vključuje produktivne impulze nevroznanstvenih in deleuzovskih paradigem.

\footnotetext{
${ }^{6}$ Zato se je C. Breger odločila za drugačen pristop, kakor sem opozorila že prej v op. 4.
} 
Pri razvitju svojega sinkretičnega pojmovanja se C. Breger opira na dialog med različnimi koncepti svetovljenja, svetotvorja (worldmaking), ki so v obtoku v teorijah pripovedi in afekta ${ }^{7}$ in na Bruna Latoura. Čeprav Latour deluje zunaj obeh področij, po njenem tesno resonira z njima. Njegova metodologija je za gradnjo ali združevanje tega, kar imenuje skupni svet (common world) še posebej uporabna zaradi eksplicitnih prepletov ontologije in teorije pripovedi. C. Breger definira pripovedno svetotvorje takole:

[]e performativni proces konfiguriranja afektov, asociacij, pozornosti, izkušenj, vrednotenj, oblik, materiala, percepcij, čutov, smisla, toposov in tropov $v$ in skozi specifične medije, ki vključujejo mentalne operacije, grafične zapise, besede in kretnje, podobe in glasove. Na področju literature, filma ali gledališke uprizoritve so ti procesi trdno sidrani $v$ retorične zanke zgradbe (ali produkcije) in branja (ali občinstva). $\mathrm{V}$ teh zankah je aktivnost svetotvorja razdeljena $\mathrm{v}$ literarni obtok med številnimi agenti, vključno (vendar ne izključno) z avtorji, pripovedovalci, liki in bralci. Vsi ti agenti so nesuvereni v tem smislu, da ne nadzorujejo povsem svojih zaznav, spominov, zamišljanj, etičnih orientacij in dejanj. ${ }^{8}$ (»Affect and Narratology« 242)

Vendar C. Breger predlaga, da se vse udeležence procesa jemlje resno, saj je vsak pomemben v kolektivnem svetotvorju, čeprav ne vedno tako, kot bi si sam želel. Ker proces pripovednega svetotvorja združuje različne vire, je tako mogoče reči, da konstituira večdimenzionalne, večvektorske združke (242). Zato pripoved še ni izčrpana z obdelavo (plot) in naprej usmerjenim vektorjem dejanja, temveč je konstituirana in obogatena z vpletanjem različnih vertikalnih, horizontalnih ali ortogonalnih vektorjev afekta in občutij, asociacij in spomina, intertekstualnosti in tropov (»Affect and Narratology« 243).

Definicija C. Breger torej posreduje med različnimi pristopi k afektu, tudi tistimi onkraj teorije pripovedi. Po njenem je deleuzovski koncept svetovljenja ali afektivna zgradba sveta zasukana proti antipripovedni naravnanosti Massumijevega pristopa, ker svetovljenje naglaša ključni element tega, kar ona opisuje kot pripovedno konfiguracijo ali združek. Združek ${ }^{9}$ pri Deleuzu označuje proces ustvarjanja kompleksnih,

${ }^{7}$ C. Breger navezuje pojem svetotvorja predvsem na Paula Ricoeura (Čas in pripoved), Mauricea Merleau-Pontyja in Nelsona Goodmana, a tudi na študije afekta in Deleuzove interpretacije Spinozove filozofije ter kvirovske prilagoditve Goodmana, Hannah Arendt, Martina Heideggerja in drugih (prim. "Affect and Narratology«, str. 250-251, op. 48; glej tudi »Affects in Configuration« 230-233).

${ }^{8}$ Prevod je delo Alenke Koron.

${ }^{9}$ Združek oz. fr. agencement je Deleuzov in Guattarijev pojem (prim. Sasso in Vil- 
multiplih zvez med prepletenimi silami, ki so že vpletene, čeprav so tudi radikalno heterogene. Združki so $\mathrm{v}$ gibanju, večplastni in bogato centrifugalni, niso gladko koherentni okrog ene same sile naprej težeče trajektorije. $Z$ vidika teorije pripovedi implicira pojem svetotvorja torej premik k odpiranju koncepta pripovedi za nered vnašajoče sile afekta. In če je pripoved razumljena bolj kot konfiguracija, ne samo kot obdelava, vključuje veliko dimenzij in vektorjev $-s$ posebnim poudarkom na multiplih združbah afekta kot spetega z besedami, intertekstualnimi asociacijam, stvarmi, ljudmi, idejami, občutji, relacijami in aktivnostmi. Konkretneje, telesna intenzivnost, ki jo v meni vzbudi določena beseda ali avdiovizualni element filma, tvori integralni del svetotvorja. Afektivni odzivi na čisto konkretne stvari, npr. ime mesta, ki ga poznam, verbalna evokacija ali dejanski zvok joka, določen izpust v prekinjenem pogovoru, vsi ti odzivi so hkrati zelo osebni in družbeno posredovani in plastijo asociacije drugih tekstov in medijev z objekti iz realnega življenja ter spomini (243).

V njeni zamisli pripovedne konfiguracije ali združka so v centru narativnosti procesi (multiple) povezave, asociacije in spetosti, ne vključujejo pa zahtev po določenih trajektorijah oblikah, stopnjah ali učinkih povezav, kakršne so kavzalnost, koherentnost ali stabilnost. S tem ko je ustvarjen prostor za fluidnost in nestabilnost afektov (v razliki od emocij v kognitivnih modelih), njena zamisel poudarjeno vključuje široko vrsto eksperimentalnih in žanrskih oblik, ki jih družijo prekinitve, nelinearnosti, nekoherenca in refleksivnost. Vseeno pa C. Breger ne absolutizira prekinitvene geste avantgardnih izročil niti novejših deleuzovskih konceptualizacij, saj je po njenem produktivnost afektov bolj v svetotvorni gesti rekonfiguracije kot v izoliranih aktih prekinitve.

C. Breger resda citira Deleuza, ko pravi, da združki vključujejo stanja stvari, telesa, različne kombinacije teles, mešanice, a tudi izjave, načine izražanja in cele režime znakov (244), toda za njeno koncepcijo afektivnih svetotvornih konfiguracij je seveda pomemben Paul Ricoeur, poleg njega pa sta zanjo ključna še Latourova zahteva po reduciranju

lani 34-40), za katerega obstajajo v slovenščini različni prevodi: razporejanje, skupek, sestava, kompozicija, zveza, združenje, montaža, konstelacija, kompleks. Kot povzema Ana Hofman v delu Glasba, politika, afekt: novo življenje partizanskih pesmi v Sloveniji (str. 19, op. 19), se združek v Deleuzovem in Guattarijevem diskurzu »nanaša na nekaj, kar je sestavljeno oziroma govori o tem, da je nekaj združeno skupaj v določeno povezavo, da je nekaj skupaj v medsebojnem razmerju. Po drugi strani pa se nanaša na to, kako je nekaj sestavljeno, na sestavo oziroma ureditev nečesa (na ustroj, razporeditev, razvrstitev, porazdelitev, organizacijo). Gre za skupek, v katerem ima vsak element pomen sam zase, a vendar le v odnosu do drugih." 
razlike med stvarmi in besedami ter njegova trditev, da sta svet in vednost artikulirana. S to trditvijo Bruno Latour, nadaljuje C. Breger, hkrati detronizira in opolnomoči jezik, ki nas vrača k realnosti prav s svojo inherentno retorično naravo. Latour torej vztraja pri tem, da nas besede in simboli vračajo $\mathrm{v}$ materialne svetove, kar ji dopušča vzeti resno ontološke implikacije študijev afekta, ne da bi marginalizirala retorične procese, prek katerih potekajo literarne ali druge umetniške oblike svetotvorja. To je zanjo pot konceptualiziranja, kako utelešeni afekti in afektivno nabiti predmeti, spomini, izkušnje in asociacije ne le prekinjajo ali vdirajo $\mathrm{v}$ tekste kot sila takojšnjosti, temveč krožijo, vstopajo in sokonstituirajo pripovedne tekste (prav tam).

Fikcijski ali fikcionalizirani svetovi so odprti svetovi s poroznimi mejami in imajo bogato mrežo povezav z zunanjimi svetovi. Prav afekt je po C. Breger tisti, ki veže fikcijski diskurz na realnost. Afekti in realna telesa $\mathrm{v}$ retoričnih procesih pripovedne zgradbe in branja tudi podčrtujejo, da nismo nikoli suvereni oziroma ne moremo avtonomno nadzorovati tvorjenja sveta. Celo pri namernih dejanjih umetniškega svetotvorja so zavestne in namerne plasti prepletene $\mathrm{z}$ nezavednimi; svojega teksta torej ne pišem sam, temveč se piše z delovanjem številnih sil v svetu, ki so oblikovale moje strahove, fantazije in preokupacije ter me oskrbele $s$ toposi, žanri in drugim, da jih izrazim. Ne moremo sicer brati predvsem zato, da bi odkrili namere v razumevanju likov, avtorjev ali bralcev, ni nam pa treba nad njimi popolnoma obupati. Latour je pomembna referenca za C. Breger tudi zato, ker je opozoril na človeške in nečloveške akterje in opazovanje njihovih svetotvornih aktivnosti (245).

Produktivnost avtoričinega modela pripovednega svetotvorja bom skušala sondirati $\mathrm{z}$ deskriptivnim branjem kratke zgodbe Suzane Tratnik "Marija, pomagaj«. Tudi ta zgodba je, podobno kot ostale v zbirki Noben glas, žanrski hibrid v tem smislu, da vključuje igrivo mešanico avtobiografskih potez in fikcijske fantastike ter retorično raznolike afektivne registre preizkušajoč pripovedni glas. Pripovedovalkina pripovedna tehnika refiguracije avtobiografske izkušnje namreč v tej tridelni zgodbi, ki jo grafično razmejujeta dva večja presledka s po tremi asteriski, igrivo prepleta otroški glas protagonistke z bolj izkušenimi komentarji nekoliko starejše opazovalke preteklih dogodkov in s čustveno nabitimi glasovi drugih pripadnikov skupnosti, mame, babice, političnega sekretarja in drugih ljudi in vsi ti komentarji in registri navidez olajšujejo distanciranje. Pri tem spretno meša resne tone z ironijo, kar vzbuja komične učinke. Zaradi vsega tega ta svetotvorni združek $S$. Tratnik na presenetljivo multivektorske načine angažira bralske afekte, kar je 
še posebej razvidno v zadnjem delu zgodbe, kjer se glagolski čas hitro menja iz sedanjika $v$ preteklik in tudi prihodnjik, tako nakazujoč prostorsko in časovno raznosmernost reprezentiranih dejavnosti.

Takoj na začetku zgodbe je pojasnjeno, da protagonistka, ki je hkrati pripovedovalka zgodbe, na kolenih skrivaj zbrano moli v "napol komunistični hišiı, kar je namig na historični kontekst in realno ozadje dogajanja in hkrati na kršitev uveljavljenih norm. Med prikazom dogajanja $\mathrm{v}$ šoli bralci izvemo, da je otroke strah, ker nova razredničarka zaradi neznanja zemljepisa fizično obračunava s Terezko, ki hodi v cerkev, a je pripovedovalkina najboljša prijateljica. Pripovedovalka zato zvečer pred spanjem sanjari o maščevanju.

Ker gre Terezki učenje težje od rok, ji skuša bistrejša pripovedovalka pomagati. Toda njuno skupno učenje doma hitro prerase $\mathrm{v}$ nenavadno igro vlog: deklici se sadistično-mazohistično izmenjujeta $\mathrm{v}$ vlogah storilca (razredničarke) in žrtve (Terezka), igra pa dobi napol "obsceno" vsebino: pripovedovalka nariše Terezko golo in $\mathrm{z}$ razredničarkino palico v Terezkinih genitalijah. Njune igre se nadaljujejo kar nekaj časa, dokler v šoli ene od risb, ki jo je narisala Terezka, ne prestreže učiteljica. Zagrozi jima, da jo bo pokazala njunim staršem in prestrašena pripovedovalka takoj izda Terezko. Ampak zaradi tega je, kot je videti, ne grize vest in ne občuti krivde. Pač pa je obe deklici izredno strah, da bi za risbo izvedeli starši, prav tako pa bralci lahko ugibamo, če se morda bojita ponižanja zaradi izgube zasebnosti, ki jo povzroči razredničarkino ravnanje. Vsekakor sošolcem, ki ju neuspešno na vse načine pregovarjajo, nikakor nočeta povedati, kaj je bilo pravzaprav na prestreženem listu papirja.

Po prvi prekinitvi pripovedi sledi srednji del, $\mathrm{v}$ katerem deklici iščeta rešitev pred sramoto, ki ju bo doletela na roditeljskem sestanku. Ena možnost, o kateri resno razpravljata, bi bila, da bi pokončali razredničarko, vendar se ne moreta poenotiti glede morilskega orožja (kamen, kramp, motika, podganji strup, električna pištola za ubijanje živine). Še slabša ideja se jima zdi, da bi jo prosili odpuščanja:

Ko sva se že sprli, kar je bilo zadnje čase pogosto, saj se nisva več igrali, sva le opustili morilske naklepe. Še bolj nora možnost od naklepnega uboja je bila, da se skesano privlečeva do razredničarkine pisarne, ponižno potrkava in jo prosiva odpuščanja. Vse, samo da vrže tisto umazano risbo v smeti in je nikoli ne pokaže najinim ubogim staršem, ki niso nič krivi, da imajo tako pokvarjeni hčeri. (Tratnik 31)

Terezka predlaga molitev k sv. Mariji, ker se tej grešniki smilijo, »medtem ko je Bog pravičen«, pojasni pripovedovalki (34). »A slednjič sva 
le izbrali molitev, kajti če bi izbrali zakol učiteljice, bi pristali v zaporu ter zamudili šolo v naravi in poletje $\mathrm{v}$ Baški. Bili bi samo še $\mathrm{v}$ zaporu in nikoli ne bi znali plavati kravla" (35), razvije svojo logiko protagonistka. Njena molitev pa je karseda neobičajna:

Marija, sveta pomagavka, pomagaj mi, grešnici, in ne kani, da učiteljica pokaže svinjsko risbo najinim staršem. Mislim mojim in Terezkinim. Naj ji zgori risba, naj magari umre, če se ne bo dalo urediti drugače. (Prav tam)

Najbolj intriganten je tretji, sklepni del zgodbe, ko postane čisto jasno, da v Mariji, pomagaj nikakor ne gre za nekakšno veristično "transkripcijo" sveta, ampak prej za afektivno nasičeno »konstrukcijo« oziroma za ukinitev opozicije med njima. Ta del bi lahko imeli tudi za hipotetično fokalizacijo, ki je eden od tipov virtualne pripovedi v smislu, kot jo je opredelila in tipološko ter deskriptivno razčlenila Snežana Milosavljević Milić (37-50). Mama se odpravi na roditeljski sestanek v elegantni opravi, kupljeni za volitve - »eleganca je nujna, kadar je v središču bodočnost", ironično komentira pripovedovalka, ki jo opazuje od daleč, z roba judovskega pokopališča. Pripovedovanje nenadoma preide v prihodnjik, ko deklica sklepa, kaj bo na sestanku, kjer sama ni prisotna, in se nato vrne v sedanjik, ko se sestanek v razredu kot da bliža koncu in razredničarka načne temo "neprimernega likovnega izražanja«. Če vzamemo vse akterje v pripovedi resno, bi lahko rekli, da nas zadnji del pripovedi plastično sooči z multipliciteto perspektiv, ne da bi ponudil edino veljavno resnico, eno in edino pravo zgodbo; možne so namreč različne alternativne, paralelne različice. Posledica tega sta decentralizacija in destabilizacija "realnosti« zgodbe, kakršni sta pogosti v literaturi postmodernizma. ${ }^{10}$

Razredničarka sprva neuspešno išče $\mathrm{v}$ svoji beležnici, iz katere končno pade list papirja prav pred noge političnega sekretarja, ki na njem zagleda podobo sv. Marije s prstom, uperjenim na lastno srce. Učiteljica je zelo zmedena in postane jo strah, kar je razumljivo v kontekstu "komunistične države«. Naslednja pograbi list z risbo Terezkina mama in vidi nekaj čisto drugega: risbo razredničarke $s$ krampom $v$ glavi in rano, iz katere odteka kri. Nato list pograbi še Terezkin oče, ki vidi Terezko golo, krvavo med nogami in z modro rutico, zavezano čez oči, kar lahko bralec kontekstualizira kot incestuozni privid ali morda strah pred njim. Oba Terezkina starša se nato nekaj prerivata okrog lista papirja, ki spet poleti, in zdaj v pretekliku izvemo, da se je mnogim staršem in celo pripovedovalkini mami posrečilo videti na njem okorno narisano razredničarko,

${ }^{10}$ Zgodbe v zbirki Noben glas sem s postmodernizmom povezala že v članku »Pripovedni prostor $\mathrm{v} » I$ Inini kocki« Suzane Tratnik. 
ki s palico maha po goli zadnjici učenke pred zemljevidom. V splošnem prerivanju, ki je nastalo - zdaj se pripovedovanje spet premakne v sedanjik -, nekateri niso videli ničesar, list pa se je odvrtinčil skoz okno v večerni mrak.

Razredničarka začne na gosto govoriti o tem, kako ogabno je, če deklici rišeta genitalije in se temu celo smejita. Starši jo z nelagodjem in zgroženi gledajo. Politični sekretar pa na videz začudeno reče: "In taki še učijo na državni šoli!« Po prvomajskih praznikih dobijo učenci namesto razredničarke novega učitelja, ki je napreden in imajo zanj vsi enake možnosti in dolžnosti, kot ironično komentira pripovedovalka, kar pomeni, da je Terezkina usoda do konca osnovne šole prejkone zapečatena. Toda papir še valovi v zraku in po svetu in riše svojo blazno geografijo, izvemo prav na koncu zgodbe, in "neprimerna risba na njem včasih najde svoje oči« (41).

In zdaj končno $\mathrm{k}$ razmisleku, kako je $\mathrm{z}$ afektoma $\mathrm{v}$ naslovu mojega prispevka in v zgodbi »Marija, pomagaj«. Sram in krivda sta afekta, z razlago katerih je nastala zdaj že popolnoma diskreditirana sociološka delitev med kulture krivde in kulture sramu. ${ }^{11}$ Po tej konservativni delitvi, ki jo je vpeljala antropologinja Ruth Benedict, naj bi bila krivda značilna za napredne kulture, katere člani imajo "vgrajen " notranji princip moralnosti, sram pa za "primitivne« kulture, ki se morajo zanašati na strinjajoč ali neodobravajoč pogled drugih ljudi, ki nadzoruje moralnost. A po mnenju Joan Copjec v članku »The Object-Gaze, Shame, Hejab, Cinema» sram in krivda $\mathrm{v}$ resnici ne definirata vrst kulture, ampak subjektovo razmerje do lastne kulture, če jo pojmujemo kot sklop tega, kar ob rojstvu podedujemo od naših prednikov, torej družino, raso, etničnost, nacionalno identiteto (13). Izkusiti sram torej ne pomeni izkusiti sebe kot degradirani objekt, ampak sebe kot subjekt (15).

Toda afekt, o katerem eksplicitno govori pripovedovalka »Marije, pomagaj«, je vendarle predvsem tesnoba oziroma strah, ki pa ni izkušnja izgube nečesa, kar se je zgodilo, temveč izkušnja pričakovanja nekega dogodka, ki se (še) ni zgodil (18). Kot povzema J. Copjec, ki se sklicuje na psihoanalitike in filozofe, pa je afektoma strahu in sramu skupno, da dajeta signal za beg in pobeg, za pobeg $\mathrm{v}$ družbenost (sociality). Zato ni presenetljivo, da se zgodba $S$. Tratnik sklene z dozdevnim, virtualnim odzivom širše skupnosti na dekliški "greh«. Saj tudi tesnobo redko izkusimo izolirano, ampak prav v povezavi s sramom in krivdo kot naj-

${ }^{11} \mathrm{~K}$ tej diskreditaciji je veliko prispevala prav E. Kosofsky Sedgwick v delu Touching Feeling: Affect, Pedagogy, Performativity (2003), ki je prevedeno tudi v slovenščno. Prim. slov. prevod, str. 52-54. 
bolj družbenima afektoma. In zelo značilno za pripovedovalkino etiko v naši zgodbi je, da se "Marija, pomagaj« ne ukvarja s krivdo, ampak predvsem $s$ sramom kot za subjekt konstitutivnim afektom, in izzivalno konča s pogledom (družbenega) drugega, pogledom, ki pripada nam (bralcem) kot nepogrešljivim posrednikom med predmetom lastnega užitka in subjektom pripovedi.

\section{LITERATURA}

Breger, Claudia. "Affect and Narratology«. The Palgrave Handbook of Affect Studies and Textual Criticism. Ur. Donald R. Wehrs in Thomas Blake. Cham: Palgrave Macmillan, 2017. 235-257.

Breger, Claudia. "Affects in Configuration: A New Approach to Narrative Worldmaking«. Narrative 25.2 (2017): 227-251.

Copjec, Joan. »The Object-Gaze: Shame, Hejab, Cinema». Filozofski vestnik 27.2 (2006): 11-29.

Flesch, William. Comeuppance: Costly Signaling, Altruistic Punishment, and Other Biological Components of Fiction. Cambridge, MA: Harvard University Press, 2007.

Hofman, Ana. Glasba, politika, afekt: Novo življenje partizanskih pesmi v Sloveniji. Ljubljana: Založba ZRC ZRC SAZU, 2015.

Hogan, Patrick Colm. Affective Narratology: The Emotional Structure of Stories. Lincoln in London: University of Nebraska Press, 2011.

Keen, Suzanne. Empathy and the Novel. New York: Oxford University Press, 2007.

Koron, Alenka. "Pripovedni prostor v 'Idini kocki' Suzane Tratnik«. Prostori slovenske književnosti. Ur. Marko Juvan. Ljubljana: Založba ZRC, ZRC SAZU, 2016. 299-311.

Kosofsky Sedgwick, Eve. Dotik občutka: Afekt, pedagogika, performativnost. Prev. Tanja Velagić. Ljubljana: Zavod Emanat, 2007.

Kosofsky Sedgwick, Eve, in Adam Frank (ur.). Shame and Its Sisters: A Silvan Tomkins Reader. Durham in London: Duke University Press, 1995.

Milosavljević Milić, Snežana. Virtuelni narativ: Ogledi iz kognitivne naratologije. Niš; Novi Sad; Sremski Karlovci: Izdavačka knjižarnica Zorana Stojanovića, 2016.

Phelan, James. Experiencing Fiction: Judgments, Progression and the Rhetorical Theory of Narrative. Columbus: Ohio State University Press, 2007.

Sasso, Robert, in Arnaud Villani, ur. Le vocabulaire de Gilles Deleuze. Nice: Centre de Recherches d'Histoire des Idées, 2003.

Tratnik, Suzana. »Marija, pomagaj«. Noben glas. Ljubljana: Beletrina, 2016. 25-41.

Walsh, Richard. The Rhetoric of Fictionality: Narrative Theory and the Idea of Fiction. Columbus: Ohio State University Press, 2007.

Warhol, Robyn. Having a Good Cry: Effeminate Feelings and Pop-Culture Forms. Columbus: Ohio State University Press, 2003. 


\section{Shame and Guilt in the Short Story "Saint Mary, Help!" by Suzana Tratnik}

Key words: narratology / Breger, Claudia / narrative worldmaking / Slovenian literature / short story / Tratnik, Suzana / narrative technique / emotions / affects / shame / guilt

Affects and emotions have been recognized as an essential part of literary experience since Antiquity, but they were excluded from the consideration of narrative literature during the dominance of structuralism. An explicit interest in them has only emerged in narratological discourses in recent decades with the emerging paradigm of contemporary affect studies. Various influences have played a role in this, including the tradition of poetics, rhetoric and psychoanalysis, recent neuroscientific, cognitive and evolutionary approaches to narrative, as well as feminist narratology, queer theoretical conceptualizations of feelings, and more recently Deleuzian conceptions of affect. In this article, I draw on a syncretic model of narrative worldmaking developed by Claudia Breger in a dialogue with the influences listed, and taking into account Paul Ricoeur and Bruno Latour. In my reading of the short story "Saint Mary, Help!" from No Voices (2016) by contemporary writer and lesbian activist Suzana Tratnik, I try to probe the narrative productivity of shame and guilt as social affects in the process of narrative worldmaking, and shed light on the type of reader engagement her discourse invites.

1.01 Izvirni znanstveni članek / Original scientific article

UDK 82.0-3

821.163.6.09-32Tratnik S.

DOI: https://doi.org/10.3986/pkn.v43.i1.14 